\title{
Lethal prostate cancer in the PLCO cancer screening trial
}

\author{
Jonathan Shoag ${ }^{1}$, Sameer Mittal ${ }^{1}$, Joshua A. Halpern ${ }^{1}$, Douglas Scherr ${ }^{1}$, Jim C. Hu ${ }^{1,2}$, and \\ Christopher E. Barbieri ${ }^{1,2}$ \\ ${ }^{1}$ Department of Urology, Weill Cornell Medical College, New York, NY, USA
}

\begin{abstract}
The Prostate, Lung, Colorectal and Ovarian (PLCO) Cancer Screening Trial randomized men to usual care or annual prostate specific antigen (PSA) screening for six years and digital rectal examination for four years. This trial found no difference between the intervention and usual care arms of the study in the primary endpoint of prostate cancer specific mortality. The PLCO trial results have had a major impact on health policy and the rate of PSA screening in the United States. We analyzed the 13 year screening and outcomes data from the 151 participants who died of prostate cancer in the screening arm of the trial in order to better understand how randomization to screening failed to prevent prostate cancer death in these men. We found that of these men, 81 (53.6\%) either were never screened as part of the trial or had an initial positive screen. Only 17 $(11.3 \%)$ of those who died reached the sixth year of the trial with a PSA $<4.0 \mathrm{ng} / \mathrm{mL}$. The men who died in the screening arm were also older at study entry than the average PLCO participant (66 versus 62 years, $\mathrm{p}<0.001$ ). Our analysis should inform the interpretation of the PLCO trial and provide insight into future trial design.
\end{abstract}

\section{Introduction}

Prostate specific antigen (PSA) screening was widely implemented in the United States in the hopes of detecting prostate cancer at an early, curable stage [1,2]. The Prostate, Lung, Colorectal and Ovarian (PLCO) Cancer Screening Trial, the only major randomized trial of PSA screening in the United States, randomized 76,693 men aged 55-74 years to annual PSA screening for six years and digital rectal exam for four years or usual care [3-5]. Although PSA screening led to increased detection of prostate cancer, it failed to decrease prostate cancer specific mortality compared to controls. The absence of demonstrable benefit in the primary endpoint of the trial has had a major impact on health care policy and the rate of PSA screening in the community [6,7]. In this study, we describe the clinical course of men who ultimately died of prostate cancer in the screening arm of PLCO. By examining

\footnotetext{
Corresponding Author: Jonathan Shoag, MD, Weill Cornell Medical College, 525 East $70^{\text {th }}$ St, Starr 900, New York, NY 10065 , Office: 212.746 .5455 , jes9171@ nyp.org.

2 These authors jointly supervised this work and share last author Jonathan Shoag, MD jes9171@nyp.org

Sameer Mittal, MD MS sam9147@nyp.org

Joshua A. Halpern, MD jah2031@nyp.org

Douglas Scherr, MD dss2001@ med.cornell.edu

Jim C. Hu, MD MPH jch9011@med.cornell.edu

Christopher E. Barbieri, MD, PhD chb9074@med.cornell.edu

The authors have no relevant conflicts of interest.
} 
their course we can better understand the limitations of PSA screening and the applicability of the PLCO Cancer Screening Trial.

\section{Methods}

We examined 13-year prostate cancer screening and outcomes data from the PLCO Cancer Screening Trial. The design of the PLCO trial and prostate cancer death determination has been previously described [3, 4, 8]. Data was obtained from the National Cancer Institute (NCI). Analysis was limited to the screening arm of the trial. Due to withdrawal of some participants the total number in the screening arm in our dataset was 38,340 as compared to 38,343 in the 2009 trial report [3]. Due to reclassification of some events based on updated data or additional review the number of deaths decreased slightly from the published 13 year outcomes data, with 151 deaths in the screening arm and 146 in the control arm [9]. STATA IC v. 13.1 was used for all analyses. P values were generated by Kruskal-Wallis one-way analysis of variance where median and IQR are denoted, by Pearson's chi-squared test where $\mathrm{N}(\%)$ are shown, absent missing data. A waiver was obtained from the Institutional Review Board at Weill Cornell Medical College as data was de-identified.

\section{Results}

At 13 years, one hundred fifty one men were confirmed to have died of prostate cancer out of 38,340 men randomized to the screening arm of PLCO. Men who died of prostate cancer were older than the average age of men in the screening arm (median 66 vs. 62 years $\mathrm{p}<0.001$ ). The median age at randomization was 66 years (interquartile range [IQR] 61.0, 70.0) and median age of death was 74 years (IQR 69.0, 79.0). We plotted the oncologic course for each participant who ultimately died of prostate cancer in the screening arm of the trial, including the duration of negative PSA screens, the time to first positive screen, timing of biopsies, and time from diagnosis to prostate cancer death (Figure). From examining the course of these men graphically, it is apparent that 81 of the 151 men who died (53.6\%) either were never screened as part of the trial or had an initial positive screen.

The men who died of prostate cancer were aggregated into 4 groups to provide further insight into their course (Table): those who were never screened as part of the trial $(\mathrm{N}=23)$, those whose initial screen was positive $(\mathrm{N}=58)$, those who had a negative initial screen and subsequent positive screens $(\mathrm{N}=53)$, and those whose screens remained negative throughout the trial $(\mathrm{n}=17)$. Of those with an initial positive screen, 19 had biopsy delayed $>1$ year after their positive screen (Figure). The median age of the 23 men who died of prostate cancer who were never screened in the trial was 70 (IQR 64.0, 74.0) at trial entry. The men who had negative PSA screens throughout the trial had a 50\% incidence of Gleason 9-10 prostate cancer and the time from diagnosis to death was substantially shorter in these men than the other groups, 1.5 years (IQR 0.9, 2.4), perhaps suggesting that these men harbored particularly aggressive, dedifferentiated prostate cancer [10]. Plots of PSA levels by time are shown in the Supplemental Appendix. 


\section{Discussion}

The PLCO prostate cancer screening trial has been criticized for a number of reasons, namely the high rate of PSA screening in the control arm of the study, and the number of men who were screened with PSA prior to study entry [3, 11, 12]. Nevertheless, despite its limitations, this trial has, and will continue to guide policy [7, 12].

In this study, we describe the course of the men who died of prostate cancer despite randomization to intensive prostate cancer screening. One of the more notable findings is that 81 of the 151 of the men who died (53.6\%) were either were not screened as part of the trial or had an initial positive screen. Of these, 23 men were never screened as part of the trial, with a median age of 70 (IQR 64.0, 74.0) at trial entry. An additional 58 men had an initial positive screen, with a median age of 66 (IQR 63.0, 70.0) at study entry. While it is unknown if earlier detection and treatment would have changed the outcome in these participants, many of these men likely had advanced disease at study entry or would have benefited from improved compliance with screening. These results suggest that perhaps the diminished use of PSA testing in all men that has resulted in part from the results of this trial is premature.

Nevertheless, the 17 men who reached the end of the trial with a PSA $<4.0 \mathrm{ng} / \mathrm{mL}, 12$ of whom also had a rectal exam that was not suspicious cancer, highlight that some lethal cancers will not be detectable by current screening techniques no matter how rigorous, and alternative biomarkers must continue to be developed to improved the detection of lethal prostate cancer. Additionally, longer follow-up may further elucidate the limitations of screening that are not yet evident.

Looking granularly at the subset of men who died of prostate cancer in the screening arm of PLCO further characterizes the primary endpoint of a study that has profoundly impacted medical practice in the United States $[6,7,12]$. By focusing on the men who died in the screening arm of trial, we can better understand how despite randomization to PSA screening these men ultimately died of prostate cancer.

\section{Supplementary Material}

Refer to Web version on PubMed Central for supplementary material.

\section{Acknowledgements}

The authors thank the National Cancer Institute for access to NCI's data collected by the Prostate, Lung, Colorectal and Ovarian Cancer Screening Trial. The statements contained herein are solely those of the authors and do not represent or imply concurrence or endorsement by NCI.

\section{References}

1. Catalona WJ, et al. Measurement of prostate-specific antigen in serum as a screening test for prostate cancer. N Engl J Med. 1991; 324(17):1156-61. [PubMed: 1707140]

2. Catalona WJ, et al. Detection of organ-confined prostate cancer is increased through prostatespecific antigen-based screening. JAMA. 1993; 270(8):948-54. [PubMed: 7688438] 
3. Andriole GL, et al. Mortality results from a randomized prostate-cancer screening trial. N Engl J Med. 2009; 360(13):1310-9. [PubMed: 19297565]

4. Andriole GL, et al. Prostate cancer screening in the randomized Prostate, Lung, Colorectal, and Ovarian Cancer Screening Trial: mortality results after 13 years of follow-up. J Natl Cancer Inst. 2012; 104(2):125-32. [PubMed: 22228146]

5. Pinsky PF, et al. Prostate cancer specific survival in the Prostate, Lung, Colorectal, and Ovarian (PLCO) Cancer Screening Trial. Cancer Epidemiol. 2012; 36(6):e401-6. [PubMed: 23000116]

6. Drazer MW, Huo D, Eggener SE. National Prostate Cancer Screening Rates After the 2012 US Preventive Services Task Force Recommendation Discouraging Prostate-Specific Antigen-Based Screening. J Clin Oncol. 2015; 33(22):2416-23. [PubMed: 26056181]

7. Moyer VA, U.S.P.S.T. Force. Screening for prostate cancer: U.S. Preventive Services Task Force recommendation statement. Ann Intern Med. 2012; 157(2):120-34. [PubMed: 22801674]

8. Miller AB, et al. Death review process in the Prostate, Lung, Colorectal and Ovarian (PLCO) Cancer Screening Trial. Control Clin Trials. 2000; 21(6 Suppl):400S-406S. [PubMed: 11189691]

9. Which states only that "In the control group, t.r.o.P.t.w.i.t.f.y.a.i.t.i.t.s.y.f.s.

10. Birtle AJ, et al. Clinical features of patients who present with metastatic prostate carcinoma and serum prostate-specific antigen (PSA) levels $<10 \mathrm{ng} / \mathrm{mL}$ : the "PSA negative" patients. Cancer. 2003; 98(11):2362-7. [PubMed: 14635070]

11. Schroder FH, Roobol MJ. ERSPC and PLCO prostate cancer screening studies: what are the differences? Eur Urol. 2010; 58(1):46-52. [PubMed: 20362385]

12. Kwiatkowski M, et al. Comment on the US Preventive Services Task Force's draft recommendation on screening for prostate cancer. Eur Urol. 2012; 61(4):851-4. [PubMed: 22285762] 
Take Home Message

In this report we looked closely at men who died of prostate cancer despite being assigned to intensive prostate cancer screening in a large US trial. The course of these men provides insight into the impact and limitations of prostate cancer screening. 


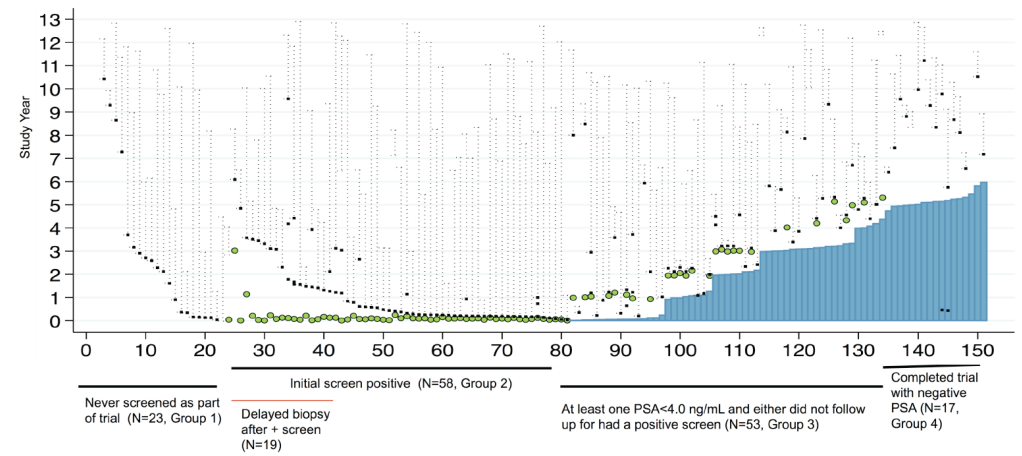

Figure 1.

History of fatal prostate cancer in the screening arm of the PLCO prostate cancer screening trial $(\mathrm{N}=151)$. 


\section{Table 1}

Characteristics of men who died of prostate cancer in the screening arm of the PLCO prostate cancer screening trial.

\begin{tabular}{|c|c|c|c|c|c|}
\hline \multirow[b]{2}{*}{ Description: } & \multirow{2}{*}{$\begin{array}{l}\text { Total } \\
\text { All men who died } \\
\text { of prostate } \\
\text { cancer in the } \\
\text { screening arm } \\
(\mathrm{N}=151)\end{array}$} & \multicolumn{4}{|l|}{ By Group } \\
\hline & & $\begin{array}{l}\text { No PSA screens } \\
\text { in trial }(\mathbf{N}=23)\end{array}$ & $\begin{array}{l}\text { Initial PSA } \\
\text { screen positive } \\
(\mathrm{N}=58)\end{array}$ & $\begin{array}{l}\text { At least one } \\
\text { negative PSA, } \\
\text { excluding } \\
\text { negative screens } \\
\text { to the end of trial } \\
(\mathrm{N}=53)\end{array}$ & $\begin{array}{l}\text { PSA screens } \\
\text { negative into last } \\
\text { year of trial } \\
(\mathrm{N}=17)\end{array}$ \\
\hline $\begin{array}{l}\text { Age At Randomization }{ }^{a} \text {, median } \\
\text { (IQR) }\end{array}$ & $66.0(61.0,70.0)$ & $70.0(64.0,74.0)$ & $66.0(63.0,70.0)$ & $65.0(61.0,70.0)$ & $62.0(60.0,67.0)$ \\
\hline $\begin{array}{l}\text { Maximum PSA (all screens) }{ }^{a} \text {, } \\
\text { median (IQR) }\end{array}$ & $5.5(3.1,13.7)$ & - & $13.7(7.5,38.6)$ & $4.0(2.8,5.4)$ & $2.0(1.4,3.0)$ \\
\hline \multicolumn{6}{|l|}{$\begin{array}{l}\text { PSA level by screen, median } \\
\text { (IQR), ng/mL, } \mathrm{N}\end{array}$} \\
\hline $1^{a}$ & $3.6(1.7,9.1)$ & - & $10.6(6.2,34.8)$ & $2.1(1.5,2.9)$ & $1.0(0.7,1.1)$ \\
\hline $2^{a}$ & $2.8(1.4,4.9)$ & - & $7.8(5.9,14.2)$ & $2.4(1.5,3.5)$ & $1.2(0.8,1.4)$ \\
\hline $3^{a}$ & $2.7(1.5,5.1)$ & - & $7.0(5.1,12.4)$ & $2.7(1.8,4.2)$ & $1.2(0.6,1.5)$ \\
\hline $4^{a}$ & $2.5(1.4,4.7)$ & - & $8.7(6.8,14.2)$ & $2.9(1.5,4.2)$ & $1.4(0.7,1.7)$ \\
\hline $5^{a}$ & $2.6(1.8,4.7)$ & - & $13.6(8.6,18.6)$ & $3.9(2.2,5.5)$ & $1.8(0.7,2.5)$ \\
\hline $6^{a}$ & $2.9(1.6,3.9)$ & - & $16.9(16.9,16.9)$ & $4.2(3.9,5.6)$ & $2.0(1.2,3.0)$ \\
\hline \multicolumn{6}{|l|}{ DRE results ${ }^{a, b}, \mathrm{~N}(\%)$} \\
\hline All negative & $24(15.9 \%)$ & $0(0 \%)$ & $7(12 \%)$ & $16(30 \%)$ & $1(6 \%)$ \\
\hline Suspicious for cancer & $56(37.1 \%)$ & $0(0 \%)$ & $31(53 \%)$ & $20(38 \%)$ & $5(29 \%)$ \\
\hline Abnormal, not suspicious & $45(29.8 \%)$ & $0(0 \%)$ & $17(29 \%)$ & $17(32 \%)$ & $11(65 \%)$ \\
\hline Never performed & $26(17.2 \%)$ & $23(100 \%)$ & $3(5 \%)$ & $0(0 \%)$ & $0(0 \%)$ \\
\hline \multicolumn{6}{|l|}{ DRE and PSA results ${ }^{a, c}$} \\
\hline $\begin{array}{l}\text { PSA }<4.0 \mathrm{ng} / \mathrm{mL}, \text { DRE not } \\
\text { suspicious }\end{array}$ & $25(36 \%)$ & - & $0(0 \%)$ & $13(25 \%)$ & $12(71 \%)$ \\
\hline $\begin{array}{l}\text { Suspicious DRE, PSA }<4.0 \\
\mathrm{ng} / \mathrm{mL}\end{array}$ & $18(32 \%)$ & - & $0(0 \%)$ & $13(25 \%)$ & $5(29 \%)$ \\
\hline $\begin{array}{l}\text { PSA }>4.0 \mathrm{ng} / \mathrm{mL}, \text { not } \\
\text { suspicious DRE }\end{array}$ & $44(64 \%)$ & - & $24(44 \%)$ & $20(38 \%)$ & $0(0 \%)$ \\
\hline $\begin{array}{l}\text { PSA }>4 \mathrm{ng} / \mathrm{mL} \text {, suspicious } \\
\text { DRE }\end{array}$ & $38(68 \%)$ & - & $31(56 \%)$ & $7(13 \%)$ & $0(0 \%)$ \\
\hline \multicolumn{6}{|l|}{ Grade (degree of anaplasia) } \\
\hline Cannot be assessed & $3(2.0 \%)$ & $0(0 \%)$ & $1(2 \%)$ & $2(4 \%)$ & $0(0 \%)$ \\
\hline Slight anaplasia (G1) & $2(1.4 \%)$ & $1(5 \%)$ & $0(0 \%)$ & $1(2 \%)$ & $0(0 \%)$ \\
\hline Moderate anaplasia $(\mathrm{G} 2)$ & $62(42.2 \%)$ & $10(50 \%)$ & $26(45 \%)$ & $22(42 \%)$ & $4(25 \%)$ \\
\hline Marked anaplasia (G3-4) & $75(51.0 \%)$ & $8(40 \%)$ & $30(52 \%)$ & $27(51 \%)$ & $10(62 \%)$ \\
\hline \multicolumn{6}{|l|}{$\begin{array}{l}\text { Number of prostate biopsies, } \mathrm{N} \\
(\%)\end{array}$} \\
\hline 0 & $6(4.0 \%)$ & $3(13 \%)$ & $0(0 \%)$ & $2(4 \%)$ & $1(6 \%)$ \\
\hline 1 & $128(84.8 \%)$ & $20(87 \%)$ & $48(83 \%)$ & $47(89 \%)$ & $13(76 \%)$ \\
\hline
\end{tabular}




\begin{tabular}{|c|c|c|c|c|c|}
\hline \multirow[b]{2}{*}{ Description: } & \multirow{2}{*}{$\begin{array}{l}\text { Total } \\
\text { All men who died } \\
\text { of prostate } \\
\text { cancer in the } \\
\text { screening arm } \\
(\mathrm{N}=151)\end{array}$} & \multicolumn{4}{|l|}{ By Group } \\
\hline & & $\begin{array}{l}\text { No PSA screens } \\
\text { in trial }(\mathrm{N}=\mathbf{2 3})\end{array}$ & $\begin{array}{l}\text { Initial PSA } \\
\text { screen positive } \\
(\mathbf{N}=58)\end{array}$ & $\begin{array}{l}\text { At least one } \\
\text { negative PSA, } \\
\text { excluding } \\
\text { negative screens } \\
\text { to the end of trial } \\
(\mathrm{N}=53)\end{array}$ & $\begin{array}{l}\text { PSA screens } \\
\text { negative into last } \\
\text { year of trial } \\
(\mathrm{N}=17)\end{array}$ \\
\hline 2 & $14(9.3 \%)$ & $0(0 \%)$ & $7(12 \%)$ & $4(8 \%)$ & $3(18 \%)$ \\
\hline 3 & $3(2.0 \%)$ & $0(0 \%)$ & $3(5 \%)$ & $0(0 \%)$ & $0(0 \%)$ \\
\hline $\begin{array}{l}\text { Year of study at diagnosis }{ }^{a} \text {, } \\
\text { median (IQR) }\end{array}$ & $2.5(0.4,5.3)$ & $2.1(0.2,3.2)$ & $0.6(0.2,2.8)$ & $3.6(2.1,5.3)$ & $8.5(7.3,9.7)$ \\
\hline \multicolumn{6}{|l|}{ Biopsy Gleason Score, N (\%) } \\
\hline $2-6$ & $31(21.1 \%)$ & $4(20 \%)$ & $15(26 \%)$ & $11(21 \%)$ & $1(6 \%)$ \\
\hline 7 & $44(29.9 \%)$ & $7(35 \%)$ & $19(33 \%)$ & $15(28 \%)$ & $3(19 \%)$ \\
\hline 8 & $24(16.3 \%)$ & $1(5 \%)$ & $11(19 \%)$ & $10(19 \%)$ & $2(12 \%)$ \\
\hline 9 & $29(19.7 \%)$ & $4(20 \%)$ & $9(16 \%)$ & $12(23 \%)$ & $4(25 \%)$ \\
\hline 10 & $8(5.4 \%)$ & $2(10 \%)$ & $1(2 \%)$ & $1(2 \%)$ & $4(25 \%)$ \\
\hline Not available & $11(7.5 \%)$ & $2(10 \%)$ & $3(5 \%)$ & $4(8 \%)$ & $2(12 \%)$ \\
\hline \multicolumn{6}{|l|}{$\begin{array}{l}\text { Prostatectomy Gleason Score, N } \\
(\%)\end{array}$} \\
\hline $5-6$ & $10(31 \%)$ & $1(33 \%)$ & $4(27 \%)$ & $5(36 \%)$ & - \\
\hline 7 & $6(19 \%)$ & $0(0 \%)$ & $3(20 \%)$ & $3(21 \%)$ & - \\
\hline 8 & $9(28 \%)$ & $1(33 \%)$ & $5(33 \%)$ & $3(21 \%)$ & - \\
\hline 9 & $7(22 \%)$ & $1(33 \%)$ & $3(20 \%)$ & $3(21 \%)$ & - \\
\hline \multicolumn{6}{|l|}{ Treatment $^{a}, \mathrm{~N}(\%)$} \\
\hline Missing Data & $4(2.6 \%)$ & $3(13 \%)$ & $0(0 \%)$ & $0(0 \%)$ & $1(6 \%)$ \\
\hline Prostatectomy & $31(20.5 \%)$ & $2(9 \%)$ & $15(26 \%)$ & $14(26 \%)$ & $0(0 \%)$ \\
\hline Radiation & $23(15.2 \%)$ & $5(22 \%)$ & $9(16 \%)$ & $9(17 \%)$ & $0(0 \%)$ \\
\hline Radiation + Hormone therapy & $28(18.5 \%)$ & $1(4 \%)$ & $14(24 \%)$ & $10(19 \%)$ & $3(18 \%)$ \\
\hline Hormone therapy only & $51(33.8 \%)$ & $10(43 \%)$ & $15(26 \%)$ & $15(28 \%)$ & $11(65 \%)$ \\
\hline Other ablative treatment & $3(2.0 \%)$ & $0(0 \%)$ & $1(2 \%)$ & $0(0 \%)$ & $2(12 \%)$ \\
\hline No known treatment & $11(7.3 \%)$ & $2(9 \%)$ & $4(7 \%)$ & $5(9 \%)$ & $0(0 \%)$ \\
\hline \multicolumn{6}{|l|}{ Prostate Cancer Stage $^{d} \mathrm{~N}(\%)$} \\
\hline 2 & $65(44.2 \%)$ & $11(55 \%)$ & $27(47 \%)$ & $21(40 \%)$ & $6(38 \%)$ \\
\hline 3 & $24(16.3 \%)$ & $0(0 \%)$ & $14(24 \%)$ & $9(17 \%)$ & $1(6 \%)$ \\
\hline 4 & $58(39.5 \%)$ & $9(45 \%)$ & $17(29 \%)$ & $23(43 \%)$ & $9(56 \%)$ \\
\hline Age of death, median (IQR) & $74.0(69.0,79.0)$ & $76.0(72.0,82.0)$ & $75.0(68.0,78.0)$ & $72.0(70.0,79.0)$ & $73.0(69.0,79.0)$ \\
\hline $\begin{array}{l}\text { Years from diagnosis to death }{ }^{a} \text {, } \\
\text { median (IQR) }\end{array}$ & $4.4(1.7,7.8)$ & $4.5(3.3,8.5)$ & $6.7(2.7,9.1)$ & $4.2(1.5,7.3)$ & $1.5(0.9,2.4)$ \\
\hline
\end{tabular}

IQR: Interquartile range, PSA: Prostate specific antigen, DRE: Digital rectal exam

${ }^{a}$ Indicates $\mathrm{p}<0.05$ for comparison between groups, $\mathrm{p}$ values generated by Kruskal-Wallis one way analysis of variance when median and IQR are denoted, by Pearson's chi-squared test where N (\%) are shown.

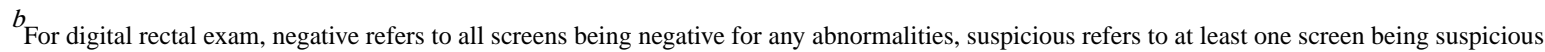
for prostate cancer, abnormal but not suspicious refers to at least one screen demonstrating other abnormalities detected on DRE that were not suspicious for cancer (eg: enlargement, tenderness).

Eur Urol. Author manuscript; available in PMC 2017 July 01. 
${ }^{c}$ Participants in whom exam was never performed excluded from analysis

${ }^{d}$ Combining clinical and pathological stage 